\title{
La recepción del léxico de la electricidad en el DRAE: de Autoridades a $1884^{1}$
}

\author{
José Antonio Moreno Villanueva \\ Universitat Rovira i Virgili (Tarragona)
}

\section{INTRODUCCIÓN}

La historia de la lengua es sin lugar a dudas una de las disciplinas que cuenta en nuestro país con mayor tradición entre los estudios lingüísticos; quizá por esa razón, es también una de las que precisa una reorientación más importante. Hoy resulta evidente que, para el adecuado estudio de la vida de nuestro idioma, no basta con acudir a las autoridades literarias, representantes de la norma culta, sino que es preciso remitirse a testimonios de distinta índole, que den cuenta de la realidad de la lengua viva, de la intrahistoria de nuestra lengua, de la que los escritores son sólo sus notarios.

Entre las distintas parcelas que conforman el estudio de la historia del idioma (fonética, morfología, sintaxis...), los trabajos sobre el léxico han ocupado siempre un lugar preeminente. Ahora bien, en la línea de lo apuntado más arriba, merece señalarse una importante carencia entre estos trabajos. Me refiero al estudio diacrónico del léxico científico y técnico, que, desde los primeros años del siglo XVIII, se convirtió en una de las principales fuentes de renovación del idioma. Durante décadas, existió la opinión generalizada de que la lengua técnica era patrimonio exclusivo de los científicos, y de que la labor del filólogo comenzaba cuando ésta ingresaba en el común del idioma. Lejos de establecer exclusivismos, hoy nadie duda que científicos y lingüistas deben aunar sus esfuerzos para preservar un bien común. Las relaciones entre lengua y ciencia abren ante nosotros un vasto campo de estudio en el que todavía queda mucho por hacer.

El estudio de la presencia del tecnicismo en el Diccionario académico (DRAE en adelante) es un capítulo de la historia de nuestra lexicografía en el que se han realizado ya algunas calas, pero que carece todavía hoy de un riguroso análisis que, más allá de las declaraciones de la Academia en las Advertencias y Prólogos al lector -fuentes de indiscutible valor documental-, nos acerque con suficiente objetividad al material léxico aco-

1 La realización de este trabajo ha sido posible gracias a la concesión de una beca pre-doctoral de Formación de Investigadores (FI-CIRIT), que avala la tesis en preparación que lleva por título El léxico científico y técnico del campo de la electricidad en el siglo XIX. 
piado en sus páginas². En este sentido, mi propósito en estas líneas es el de evaluar la penetración del lenguaje científico y técnico relacionado con la ciencia de la electricidad en las páginas del DRAE, desde la aparición del primer tomo del Diccionario de Autoridades (AUTORIDADES en adelante) en 1726 hasta la decimosegunda edición, aparecida en 1884. El detallado examen de la recepción de este vocabulario debe servir para valorar la manera como se traducen en el cuerpo del diccionario las intenciones expuestas por los académicos en los Prólogos y Advertencias a sus distintas ediciones. Por otra parte, permitirá ofrecer algunas reflexiones sobre el retraso con que los términos científicos se incorporan al caudal léxico del repertorio académico ${ }^{3}$.

\section{El NACIMIENTO dE LA CIENCIA ELÉCTRICA Y LA DIFUSIÓN DE SU ESTUdIO EN ESPAÑA}

Las propiedades atractivas del ámbar o electro (del griego hlektron, a través del latín electrum) eran conocidas ya por los antiguos ${ }^{4}$, pero ni su descubridor ni quienes lo imitaron en sus experimentos llegaron a intuir la naturaleza de aquella facultad invisible. A decir verdad, hasta principios del siglo XVII, todo lo relacionado con la electricidad y el magnetismo -ambos fenónemos aparecen frecuentemente ligados por entoncesiba poco más allá de la observación curiosa de ciertos fenónemos naturales, tales como la piedra imán, el rayo, los fuegos de San Telmo o el torpedo (MarTínez BarRios, 1994, p. 19). Es en el año 1600 cuando, de manos de William Gilbert, la electricidad y el magnetismo se someten por vez primera a un estudio experimental y científico. La publicación de la epístola De magnete marca el inicio de la historia de la electricidad y abre la época de la electrostática5.

2 Los trabajos que se han ocupado de esta cuestión han centrado su interés en el estudio de la discusión acerca del lugar que corresponde al tecnicismo en el diccionario general. En este sentido, además de los conocidos artículos de M. Alvar EzQuerRa (1983, 1985 y 1992) sobre el contenido de los prólogos del DRAE, merecen destacarse los trabajos de M. SECO (1987) y E. ANGLADA y Ma BARGALLO (1992), que se detienen en el estudio de los productos de la lexicografía no-académica.

3 El presente artículo se suma, de este modo, a una serie de trabajos que se han ocupado recientemente del estudio de la terminología desde una perspectiva diacrónica. Esta es la orientación de mi anterior estudio sobre la incorporación del léxico de la electricidad al español a través de las traducciones de las obras de J. A. Nollet (J. A. MOREnO, 1995). Otros trabajos que se sitúan en esta misma línea son los de B. GuTIÉRREz RODILLA (1993 y 1996) sobre el léxico de la medicina, los de C. GARRIGA (1995 y 1996) sobre el léxico de la química y de la economía respectivamente, o el de F. RodRíGuez (1996) sobre el léxico del ferrocarril.

${ }^{4}$ Numerosas obras señalan a Tales de Mileto (siglo VI a.C.) como el primero en observar la fuerza de atracción del ámbar amarillo (STILL. 1947, p. 19; DeVAuX, 1949, p. 20; CANBY, 1965, p. 10).

5 Distintos autores (Planell Riera, 1950, p. 4; Rosmorduc, 1994, p. 126; Martínez Barrios, 1994, p. 19) coinciden en señalar esta fecha como el inicio de la historia de la electricidad. En su estudio (cuyo título completo es De Magnete magneticisque corporibus et magno magnete tellure. Physiologia noua), Gilbert distinguía tres categorías de cuerpos, según su grado de atracción al ser frotados. A las sustancias que compar- 
Pocos progresos se hicieron a lo largo del siglo XVII. En 1672, Otto de Guericke inventaba la máquina eléctrica de globos de azufre, la primera de una serie de máquinas generadoras de electricidad estática que van a servir para que la ciencia experimental de la electricidad dé sus primeros pasos ${ }^{6}$. Ya en el siglo XVIII, habrá que esperar a los trabajos de Gray y Wheler (alrededor de 1729) sobre la conducción eléctrica, luego desarrollados por Dufay (1733), para avanzar definitivamente en los estudios sobre la ciencia eléctrica. Algunos años más tarde, Ewald J. von Kleist demostraba que el fluido eléctrico podía almacenarse; la invención en 1746 de la botella de Leyden, el primer condensador, fue la consecuencia más inmediata de este descubrimiento7.

Por entonces, la electricidad invadía las reuniones y salones aristocráticos de la mano del abad Jean-Antoine Nollet (1700-1770)8, el verdadero divulgador de los descubrimientos producidos en esta rama de la física; al tiempo, la medicina se interesó por este fluido y creyó ver en él propiedades curativas. La electricidad salió a la calle y se puso de moda.

A finales del siglo XVIII, el gran interés que despertó en el seno de la comunidad científica el estudio de la ciencia eléctrica había de dar lugar a una floración inusitada de trabajos, que abundarían en el estudio de las cargas eléctricas: Priestley (1767), Cavendish (1772), Coulomb (1785), Poisson. En 1800, mientras Alessandro Volta inventaba la pila galvánica -el primer acumulador eléctrico-, Carlisle y Nicholson descomponían el agua mediante electrólisis. Este último, junto a Davy, inventor del arco eléctrico

tían las propiedades atractivas del ámbar las llamó electrica; a la singular virtud que las distinguía dio el nombre de vis electrica. La palabra electricidad (electricity) no será empleada hasta la publicación de la Pseudodoxia Epidemica de Thomas Browne en 1646 (vid. J. A. Moreno, 1995).

6 A la máquina eléctrica inventada y descrita por Guericke en el libro Experimenta nova publicado en Amsterdam, siguió en 1709 la máquina de cilindro de vidrio, ideada por Hauksbee. Este físico inglés comprobó que la bola de azufre que había venido utilizándose para electrizar los diferentes cuerpos podía ser sustituida por una esfera o tubo de vidrio, que adquiría electricidad por medio de unos patines de fieltro o cuero que recibían el nombre de frotadores. La descripción de estas máquinas, que se utilizaron durante algo más de un siglo, se puede hallar en distintos tratados de física experimental y electricidad de la época. Tal es el caso del Ensayo sobre la electricidad de los cuerpos (1747) o las Lecciones de física experimental (1757) de J. A. Nollet, los Elementos de fisica teórica y experimental (1787) de SIGAUD DE LA FOND, o el Resumen histórico y experimental de los fenómenos eléctricos (1792), del mismo autor (las fechas consignadas entre paréntesis corresponden a su versión española).

7 Rosmorduc sostiene que la botella de Leyden fue inventada por Von Kleist en 1745 (1994, pp. 128 y 261): DEvauX, por contra, confirma que el invento debe atribuirse a Musschembroek, quien describe su experimento en una carta redactada en latín el 20 de abril de 1746 (1949, p. 43). RierA parece poner fin a la confusión: Von Kleist fue, en efecto, el primero en llevar a cabo el experimento, sin embargo, sus escritos no fueron publicados hasta 1746 por J. Gottlob Krüger, profesor de física en Halle; Musschembroek fue quien repitió ese mismo experimento, aunque con total independencia del que se ha descrito, y lo dio a conocer con anterioridad (1989, p. 52).

8 Sus Leçons de physique experimentale (1743-1748), que constaban de seis volúmenes, fueron editadas en Francia en ocho ocasiones; a ellas hay que sumar el Traité sur lélectricité des corps (1746). reimpreso en cuatro ocasiones, y las Lettres sur l'électricité, aparecidas en tres entregas (1760-1767). Para mayor detalle sobre la figura de J. A. Nollet y la difusión de su obra en España, vid. J. A. MoReno, (1995). 
(1816), perfeccionaría posteriormente el invento de Volta, del que se servirán Ampère y Faraday en sus experimentos e investigaciones para establecer la conexión entre los fenómenos eléctricos y magnéticos.

El camino quedó definitivamente abierto y los avances en esta parcela de la física fueron espectaculares en pocos años; su aplicación a diversas ciencias e industrias no se hizo esperar. La química, la medicina, la galvanotecnia o la telegrafía se vieron pronto beneficiadas por los nuevos descubrimientos.

Cuando los estudios sobre electricidad comienzan a desarrollarse en Europa, nuestro país vive, con la subida al trono de los Borbones en 1714, una etapa de recuperación económica y de prosperidad en los estudios científicos que se alargará hasta finales de siglo9. A diferencia de otras ramas de la física como la astronomía, la matemática o la mecánica, la ciencia eléctrica encuentra desde el principio el terreno abonado para la difusión de sus hallazgos y conocimientos. Las traducciones de los principales manuales y tratados de la época, de procedencia generalmente francesa -recuérdese que por entonces el francés era lengua universal y de cultura-, no se harían esperar. También nuestros sabios ensayarán sus propias obras. Así describe JuGLA y FonT el ambiente científico de la época, y el lugar que correspondía a la electricidad entre las restantes ciencias:

Gran parte de las otras ciencias, aunque puedan atribuir al presente siglo nuevos progresos y adelantamientos de la mayor utilidad, traen su origen de siglos y naciones muy remotas, y despues de haber padecido segun las vicisitudes de los tiempos notables intercadencias, han recibido ultimamente en este siglo, y deben á su ilustracion los adelantamientos que han adquirido, el estado feliz en que se ven constituidas, y el alto grado de estimacion que merecen entre los sabios; pero la Electricidad, poco conocida en los siglos pasados, quasi todo cuanto tiene, ó á lo menos quanto tiene de util y apreciable, lo debe al presente, en que los Fisicos á competencia se han esmerado en averiguar sus preciosos efectos, como que parecen empeñados á llevarla al mas alto grado de perfeccion (1788, pp. 1-2).

En 1747, tan sólo un año después de su edición francesa, Joseph Vázquez y Morales traduce el Ensayo sobre la electricidad de los cuerpos de J. A. Nollet, el primer texto relacionado con los nuevos conocimientos y experiencias desarrollados en el continente europeo. Cinco años más tarde, en 1752, ve la luz la Physica Eléctrica de Benito NAVARRO y ABEL DE VEAS, que se convertirá en la primera obra de autor español sobre electricidad. Con posterioridad, dos nuevas obras del abate Nollet se traducirán a nuestro idioma: las Lecciones de física experimental (1757), que traducirá Antonio Zacagnini; y las Cartas sobre la electricidad, que leerá ANTONı JuGLÀ y FonT en el seno de la Re-

9 Para profundizar en el estudio de las vías de desarrollo de la política científica borbónica y sus principales logros, pueden verse las obras de J. L. ABELLÁN (1993), J. VERNET (1975), J. M. LÓPEZ PIÑERO (1969 y 1979). J. AgustI I CULLELL (1983) y S. RieRA (1983 y 1989). 
al Academia de Ciencias Naturales y Artes de Barcelona desde 177310. Tras la aparición de estas primeras obras, el estudio de la electricidad se va a generalizar en nuestro país, y dará lugar a numerosas memorias y ensayos ${ }^{11}$; por otra parte, comenzará a ser habitual su presencia en los tratados de física experimental ${ }^{12}$.

Este conjunto de textos se enmarca dentro del denominado período primitivo de la electricidad, o del dominio de la electrostática (Planell Riera, 1950, p. 3). Lógicamente, muchas de las teorías y experimentos en ellos desarrollados van a ser revisados con posterioridad, e incluso rebatidos. En cualquier caso, nos van a legar una nutrida serie de términos y expresiones, calcados de los surgidos al otro lado de los Pirineos, aprovechando el común origen grecolatino. Buena prueba de ello es que el Diccionario universal de física (1796-1802) de M. J. BRISSON ${ }^{13}$, una de las obras fundamentales para la catalogación de los nuevos saberes en este ámbito de la ciencia (SAN VICENTE, 1996, p. 783), cuenta con cerca de un centenar de artículos relativos al estudio de la física eléc-

10 Las Lecciones de física traducidas por Zacagnini fueron, por espacio de treinta años, el único texto de referencia sobre física experimental que podía encontrarse en las escuelas españolas. Así se deduce de las palabras de Tadeo Lope en el 'Prólogo del traductor' a los Elementos de física teórica y experimental de SIGAUD DE LA FOND: "aunque se ha trabajado mucho en nuestras Escuelas en esta parte de la Filosofía, ha sido solamente sobre la Física Escolástica, llamada Aristotélica, y la Metafísica, de las quales hai muchos Autores Españoles que las tratan con extension, cuyas disputas sostenidas, mas por deseo de la victoria que por hallar la verdad han producido una especie de Física que toda se reduce á palabras, y á vana ostentacion de terminos de que no se saca el menor fruto; y aunque se experimenta lo contrario en la experimental, no hai sino las Lecciones de Física del Abate Nollet, traducidas por el P. Zacagnini, las quales carecen de los grandes y utilisimos descubrimientos posteriores que se han hecho de veinte y cinco años á esta parte" (1787, pp. xii-xiii). Para mayor detalle sobre ésta y las anteriores traducciones, vid. J. A. Moreno (1995).

11 Entre las traducciones destacan los siguientes títulos: C. RIEGER (1763) Observaciones Physicas sobre la Fuerza Eléctrica (trad. del P. Miguel de Benavente); SIGAUD DE LA FOND (1792) Resumen histórico y experimental de los fenómenos eléctricos (trad. de Tadeo Lope). Entre las memorias aparecidas por estos años. por otra parte, ocupan un lugar destacado las presentadas en el seno de la Real Academia de Ciencias Naturales y Artes de Barcelona por A. JUGLA Y FonT sobre la construcción y utilidad del pararrayos (1788), y las de F. SALVÁ Y CAMPILLO sobre la electricidad positiva y negativa (1778), la invención y usos del electróforo (1793). el galvanismo (1800 y 1801) y la aplicación de la electricidad a la telegrafía (1795, 1800 y 1804).

12 Las siguientes obras constituyen algunos ejemplos paradigmáticos: SIGAUD DE LA FOND (1787) Elementos de física teórica y experimental (trad. de Tadeo Lope); C. GIMBERNAT y Grassot (1787) Exercicio público de fisica experimental (1787); A. LIBES (1827-28) Tratado de fisica completo y elemental (trad. de P. Vieta).

13 La obra de BRISSON, que consta de diez volúmenes (el último de ellos, además de incluir un Suplemento, reúne distintas láminas e ilustraciones), fue traducida entre 1796 y 1802 por Cristobal Cladera y F.X.C. (a partir del segundo tomo el autor es sólo el primero). El texto, sin embargo, no era sólo una traducción. sino que, como se apuntaba en su título, venía "aumentado con los nuevos descubrimientos posteriores a su publicacion". Por otra parte, la obra -según declaraciones del propio autor - "contiene un verdadero tratado completo de Física" ('Discurso preliminar', 1796, p. viii). "No hay Obras mas á propósito para instruir al Público, deleytarle, y suministrarle los medios de satisfacer su innato deseo de saber, que los Diccionarios. pues proporcionan aun á los ménos iniciados en las Ciencias, el poderse enterar muy en breve de las qüestiones que mas le interesa saber. Así es que en este siglo se han multiplicado casi sin término en todos los ramos de las Ciencias, siendo muy de extrañar se haya descuidado en este punto una de las que con mayor razon se han cultivado mas generalmente en toda Europa", concluye BRISSON (id., p. iv). 
trica. No deben pasarnos por alto las palabras de sus traductores en el "Discurso preliminar", que ponen de manifiesto la dificultad de adaptar los nuevos conceptos a la lengua española:

Á pesar del escrupuloso cuidado con que hemos procurado traducir unas materias de una utilidad tan general, y en que se hallan voces que, ó por su novedad, ó porque no se han cultivado en España, no tienen su correspondencia exacta en nuestra lengua, quizá no habrémos acertado alguna vez á dar el verdadero sentido: pero debemos decir para satisfaccion del Público, que hemos consultado para no errar todas las Obras maestras que tenemos en nuestra lengua, que nos han podido suministrar alguna luz; que hemos recurrido á sábios Profesores quando hemos dudado, ó no nos hemos fiado de nuestro propio parecer; y que repetidísimas veces hemos recorrido los talleres públicos de esta Corte, para presenciar las operaciones y cerciorarnos por los mismos Artistas, acerca de lo que no nos indicaban con claridad los mismos libros (1796, t. I, pp. xxvii-xxviii)

\section{LA RECEPCIÓN DEL LÉXICO DE LA ELECTRICIDAD EN EL DRAE}

\subsection{De Autoridades al DRAE-1791}

El sucinto panorama dibujado en el anterior apartado sirve para ilustrar que la ciencia de la electricidad nace prácticamente a la par que el Diccionario de Autoridades. No debe extrañar entonces el que los pocos términos relacionados con esta disciplina que aparecen en las primeras ediciones del repertorio académico no sólo no pertenezcan estrictamente al ámbito de los fenómenos eléctricos tal como se conocen en nuestros días -se trata de voces que se relacionan también con el estudio del magnetismo-, sino que ni siquiera se reconozcan hoy como tecnicismos.

En diferentes ocasiones se ha señalado que el Diccionario de Autoridades, punto de partida del resto de ediciones del diccionario académico -en especial de las primeras- dejó de lado el léxico relacionado con las ciencias y las artes, reservándolo para una obra distinta ${ }^{14}$. A pesar de la voluntad de los primeros académicos, lo cierto es que en esta

14 La Academia se mostró reacia desde el primer momento a la inclusión generalizada de los tecnicismos en el cuerpo de su repertorio, no dejándose impresionar por la invasión que había tenido lugar en el siglo del progreso de las ciencias y de la técnica; sólo se incorporarían aquellos que estuvieran autorizados por célebres escritores. A pesar de todo, los académicos no querían olvidarse de los tecnicismos que se habían ido incorporando paulatinamente al caudal general de la lengua. Por una parte. en la segunda edición de AuTORIDADES (1770) -sólo vio la luz el primer tomo-, mostraban de manera explícita su voluntad de recoger, de tales voces, aquellas "que están recibidas en el uso común de la lengua, sin embargo de que la Academia pensó antes ponerlas todas". Por otra, en los Estatutos y prólogos a los distintos tomos de la primera edición, los 
obra pueden encontrarse numerosas voces procedentes del ámbito científico ${ }^{15}$.

Como el resto del léxico, el que se relaciona con la electricidad, y en general el relativo a las disciplinas científicas, se extrae de las obras literarias con que contaban los miembros de la Corporación. Sólo en algunas ocasiones éste se complementaba con algunos textos de la materia, cuya selección no parece observar ningún tipo de criterio. De hecho, esta característica se explica si se tiene en cuenta que los académicos dieciochescos entendían el Diccionario como un instrumento para "cultivár, y fijár la pureza, y la elegancia de la lengua Castellana" (Estatutos), esto es, para establecer su norma culta, acudiendo a la mejor tradición literaria. No era su propósito dar cuenta de un tipo de términos que entonces se reservaba a los hoy denominados 'diccionarios enciclopédicos'. Las palabras relacionadas con el ámbito científico interesaban, no para un mayor y mejor conocimiento de la realidad, sino, fundamentalmente, para entender las obras literarias (GutiérReZ Rodilla, 1993, p. 471).

Tras lo apuntado sobre estas líneas, no sorprende que en AUTORIDADES se incluyan solamente tres voces que merezcan algún tipo de comentario. Se trata del verbo atraher, y de sus derivados atraccion y atractivo, cuya definición, al mencionar las propiedades atractivas del azabache, remite a los conocimientos y experiencias de los antiguos en materia de electricidad ${ }^{16}$.

ATRAHER. Traher hácia sí alguna cosa, hacerla venir sin violéncia: como hace el Imán al hierro, ò el azabáche à la paja. Es voz compuesta de la partícula $\mathrm{A}, \mathrm{y}$ del verbo Traher, y tiene sus mismas anomalías. Hállase freqüentemente escrito sin la h, diciendo Atraer; pero es contra su orígen. Lat. Attrahere. comend. sob. las 300. fol.19. Syrtes son lugáres peligrosos de la mar... dichos assi de Syrin, verbo Griego, que quiere decir atraher. Acost. Hist. Ind.lib.3.cap. 27.Que tienen virtúd de atraher à sí matéria vaporosa, y convertirla en água.

Aunque se trata de fenómenos físicos que observan notables similitudes, lo cierto es que en la explicación se confunde la manifestación del magnetismo y la electricidad

miembros de la Institución expresan repetidamente su intención de realizar un diccionario facultativo: "De las voces própias pertenecientes à Artes liberales y mechánicas ha discurrido la Academia hacer un Diccionario separado, quando este se haya concluído: por cuya razón se ponen solo las que han parecido mas comúnes y precisas al uso, y que se podian echar de menos" (AUTORIDADES, 1726. p. v). A pesar de las promesas académicas, nunca hasta nuestros días la Corporación ha vuelto a mostrar la intención de confeccionar un repertorio de similares características. En opinión de diversos autores (Alvar EzQUeRRA, 1992, p. 20; PASCUAL-GutiérREZ, 1992. p. xxvi), el Diccionario castellano con las voces de ciencias y artes (1786) del padre E. DE TERREROS vino a suplir la voluntad de la Academia.

15 El estudio de GutiérRez Rodilla (1993) sobre los términos relacionados con la medicina que se incluyen en AUTORIDADES hace evidente la inclusión de auténticos tecnicismos, en franca contradicción con las ideas expuestas por la Academia.

16 Obsérvense las puntualizaciones que, sobre la grafía. se realizan en la definición de atraher, donde se justifica la colocación de la $h$ entre vocales, acudiendo a su etimología; emparentar la lengua castellana con la lengua latina era también una manera de ensalzarla y embellecerla. 
(estática) respectivamente. No puede tildarse de errónea la definición ofrecida por los académicos en este punto, sin antes conocer el estado de los estudios sobre el tema por esos años. Baste recordar, en este sentido, que si bien los fenómenos eléctricos eran ya sometidos por entonces a la atenta observación de los científicos de la época, no es menos cierto que los sabios no acababan de explicarse su analogía con la virtud magnética. Por otra parte, los efectos de atracción eléctrica, junto a la repulsión y las emanaciones luminosas, van a ser las únicas manifestaciones conocidas de este agente invisible durante la época del dominio de la electrostática.

La inclusión y calidad del material léxico del ámbito de la electricidad atesorado por el diccionario académico -como el relativo a otras áreas científicas- no experimentará grandes cambios con la reducción del repertorio a un solo tomo, al margen de la supresión de las autoridades y las etimologías. Piénsese que, mientras no se abandone la tarea de revisión de AUTORIDADES, el diccionario en un solo volumen no adquirirá entidad propia; sólo entonces se convertirá en el centro de la actividad lexicográfica académica. Como cabía esperar, tras la aparición de las tres primeras ediciones del DRAE (en 1780, 1783 y 1791), el caudal léxico relativo a los estudios de la electricidad, a pesar del notable desarrollo adquirido por estas ramas de la física desde la publicación de AuTORIDADES, continuará siendo escaso, viéndose incrementado tan sólo con una nueva acepción. Se trata del adjetivo atractriz, incorporado en el DRAE-1791, y definido como sinónimo de atractivo en el sintagma 'la virtud atractiva. Vis, facultas attrahendi ${ }^{17}$.

No cabe la menor duda de que, hasta aquí, el repertorio se nos ofrece como un compendio de AUTORIDADES. El hecho de que las definiciones se trasladen, casi palabra por palabra, al cuerpo del diccionario en un solo volumen así parece confirmarlo. Una excepción a esta evidencia, no obstante, es la que se observa en las voces atraccion y atractivo, que en AUTORIDADES se definían en términos similares a atraher, y que, en el $D R A E-1780$, ven simplificada notablemente su explicación ${ }^{18}$.

17 Aunque se trata de expresiones sinónimas, el sintagma virtud atractiva (en ocasiones facultad atractiva) es más utilizado que virtud atractriz en los textos que versan sobre electricidad o física general, a juzgar por las documentaciones que he podido hallar, de las que ofrezco sólo una. Mientras el primero es utilizado por Nollet (1747), p. 8. SiGAUd DE LA Fond (1792), p. 4 y BRISSON (1796-1802), el segundo sólo se documenta en Nollet (1747), p. Ix. Dado que la virtud atractiva se entiende también como la acción del magnetismo, es la expresión virtud eléctrica la habitualmente empleada en los manuales para designar la facultad de atraer los cuerpos ligeros que poseen ciertos minerales al ser frotados: vid. NollET (1747), p. vi, SIGAUD DE LA FOND (1792), p. vii. BRISSON (1796-1802), LIBES (1827-28), p. 123.

18 Atraccion se define como 'la accion o virtud de atraer. Attractio'; atractivo como 'Lo que tiene virtud de atraer. Attrahendi efficax'. No deja de ser significativo que se modifiquen tales términos, pues, según indica el Prólogo, en la edición de 1780 "las letras A, B y C se han puesto con la corrección y aumento que tienen en el tomo primero de la segunda impresión [del Diccionario de Autoridades]" (DRAE-1780). 


\subsection{Del DRAE-1803 al DRAE-1843}

En el Prólogo a la cuarta edición del $D R A E$ (1803), la Academia se muestra continuadora en la defensa del criterio purista y normativista, manteniéndose firme en su postura de no incluir más voces que las debidamente consagradas por el uso. En buena lógica, la nomenclatura científica quedará apartada del repertorio oficial edición tras edición, hasta 1843. Por otra parte, aunque "llega la Academia con el trabajo de revision hasta la L inclusive" (DRAE-1803), pronto se vislumbra que esta nueva impresión del diccionario en un solo volumen es algo más que una presentación compendiada de los materiales que resultan de ese trabajo19. Por primera vez desde su edición 'reducida', el diccionario presenta incorporaciones y correcciones en todas las letras, que no resultan exclusivamente de la tarea de revisión de AUTORIDADES ${ }^{20}$. El DRAE inicia su andadura hacia la autonomía, que será ya inminente en 1817.

La tímida apertura del repertorio se traduce en la incorporación de tres nuevas voces pertenecientes al ámbito de la ciencia eléctrica. Sin duda, la más significativa y relevante para el presente estudio es la inclusión del término electricidad, que se define como sigue:

ELECTRICIDAD. Materia sutilisima, y muy fluida, diversa de los demas fluidos por sus propiedades, y comunicable á todos los cuerpos á unos mas que otros: produce varios efectos y muy extraños, y uno de los mas conocidos es el de atraer, y repeler los cuerpos leves, y la propiedad de los cuerpos que tienen esta materia. Esta voz y sus derivados se ha introducido modernamente. (DRAE-1803)

La definición ofrecida sobre estas líneas evidencia el escaso nivel que los conocimientos sobre este fluido habían alcanzado hasta el momento; tan sólo se apunta su capacidad de transmisión, y los efectos de atracción y repulsión que se derivan de su aplicación. El léxico relacionado con los nuevos trabajos y hallazgos surgidos como consecuencia de su estudio científico deberá esperar todavía algunos años hasta verse reflejado en el repertorio académico. No resulta extraño, en consecuencia, el que en la explicación del término electricidad se acabe puntualizando que "Esta voz y sus derivados

19 "queriendo satisfacer á las insinuaciones de muchas personas, que deseaban se pusiesen las voces que faltaban en las otras letras, ha intercalado en todas ellas quantas poseia, y quantas han recogido los actuales individuos de la Academia, corrigiendo asímismo algunos artículos de estas combinaciones, añadiendo además varias voces á las letras anteriores, y mejorando las definiciones de otras" (DRAE-1803).

20 Las razones de este cambio de postura parecen claras. Dado el apego del repertorio común al trabajo de revisión de AUTORIDADES, el diccionario en un solo tomo tampoco podría llegar a reflejar la realidad lingüística del momento, el uso real de la lengua, sin adquirir entidad propia; cuando la Academia acababa la revisión de uno de los tomos en vistas a la segunda impresión de su primera obra, ya existían nuevos materiales para la revisión de los que ya se daban por finalizados. De seguir el ritmo que se llevaba hasta entonces. la edición completa revisada de AUTORIDADES habría aparecido alrededor de 1825, jcasi medio siglo después de la revisión de sus primeras letras, aparecida en 1770 ! 
se ha introducido modernamente". Sus primeras documentaciones se hallan en la traducción del Ensayo (1747) de J. A. Nollet. Ésta es la definición ofrecida por el sabio francés:

Llamase assi la accion de un cuerpo, que se pone en estado de atraer à sì, ò repeler (como se vè en el Ambar) las pequeñas pajas, plumas, ù otros cuerpos ligeros, que se le presentan à cierta distancia. La Electricidad se manifiesta principalmente de dos modos; el primero: Por movimientos alternativos que se expressan con los nombres de atracciones, y repulsiones; el segundo: Por una especie de inflamacion. que toma diferentes formas, y tiene diferentes efectos, segun las circunstancias $(1747, \text { p. } 1)^{21}$.

A pesar de su señalada modernidad, sin embargo, ni la voz electricidad, ni sus derivados eléctrico ('Lo que tiene ó comunica electricidad, ó lo que pertenece a ella') y electrizar ('Comunicar la electricidad á algun cuerpo'), incorporados también en el DRAE1803, aparecen acompañados de la marca diatécnica Fís., que debería corresponderles como tecnicismos22.

Cabe apuntar, también en esta edición, la incorporación de la electricidad en la explicación de ciertos fenómenos naturales. La voz rayo, que se incluía en el léxico oficial desde AUTORIDADES, se define por primera vez acudiendo a su naturaleza eléctrica, que había sido advertida por Franklin en 1746: 'Fuego electrico vivísimo que procediendo de una nube electrizada, se manifiesta contra algun objeto terreste [...]' (DRAE-1803).

21 CoRominas-Pascual (1980) sitúan la aparición de este término, y la de sus derivados eléctrico y electrizar, en el Diccionario de TeRREROS (1786-1793), donde se definen como sigue:

'ELECTRICIDAD, termino de Fisica, y de la Historia Natural, cualidad, ó virtud de algunos cuerpos, que atrahen. ó apartan á otros. Fr. Electricité. El Lat. que le dán es Electrícitas, virtus attráctiva, \&c. Elettricitá.'

'ElECTRICO, CA, adj. que se dice del cuerpo, ó materia que tiene electricidad. Fr. Electrique. Lat. Eléctri vim habens. It. Elettrico. La Máquina electrica, es un medio, ó instrumento para vér las curiosas, y admirables experiencias, que nos han manifestado muchos sabios, especialmente en este siglo, V. Nollet, Jalabert, Navarro, Rieger, \&c.'

'EleCtRIZÁr, voz de la Filosofia, hacer eléctrico, comunicar la electricidad. Fr. Electrisér. Dánle el Lat. Eléctricum réddere, electricitátem impertíri.'.

En el Ensayo de Nollet -traducido por Vázquez y Morales-, además de estos términos, que se documentan también en SIGAUD dE LA FOND (1787 y 1792). GIMBERNAT (1787), JUGLA (1788) y BRISSON (17961802), se observa la presencia de las voces electrizacion (1747). p. 12 -se incorpora a partir del DRAE-1884. electrizable (1747), p. 91 -se incorpora a partir del DRAE-1914-, electrificar y electrificacion (1747), p. 14.

22 Desde 1780 el repertorio académico incorpora un sistema de marcas por abreviaturas que, abundando en la reducción de la información, sustituye a la indicaciones y comentarios sobre el uso que se ofrecían en AUTORIDADES: "En calidad y censura de las voces se ha usado de varias abreviaturas, cuya explicación se pone al principio del tomo" (DRAE-1780). Para el presente estudio interesan solamente las marcas diatécnicas. En este sentido, es la marca Físic. o Fís. -introducida desde la primera edición en sustitución de la indicación Voz de la fisica- la que acompaña a los términos que se derivan del estudio de las ciencias físicas. La marca Electr., para las voces relacionadas con la electricidad, no se incluye en el DRAE hasta 1925. 
La quinta edición del $D R A E$ (1817), en un nuevo paso hacia la consolidación del repertorio en un solo volumen, elimina de su título el hasta entonces habitual añadido 'reducido á un tomo para su mas fácil uso'. En las líneas del Prólogo, el diccionario se concibe ya como una obra independiente, con fin en sí misma, con entidad propia; buena prueba de ello es el importante proceso de revisión a que dice someterse: "se han aclarado y rectificado muchas definiciones" y "se han suprimido tambien muchas palabras y expresiones redundantes, y varias noticias y etimologías que han parecido poco necesarias y oportunas" (DRAE-1817). El DRAE, aunque fiel a su criterio conservadurista, continúa actualizándose. En el ámbito del presente estudio, tal circunstancia se traduce en la incorporación de cinco nuevas voces que vienen a designar elementos y hallazgos relacionados con la electricidad: fluido eléctrico, fluido galvánico, pararayo, ámbar y electro. Las dos primeras se derivan del desarrollo de sus estudios 23 :

FLUIDO ElÉCTRICO. Nombre que se da al que se desprende de diferentes cuerpos, principalmente por la frotacion, y que produce los efectos que conocemos por electricidad. Fluidum electricum.

FLUIDO GALVÁnICO. El flúido eléctrico que se desprende por el contacto de dos metales diferentes; como el zinc y el cobre, y otros cuerpos de distinta naturaleza. Fluidum galvanicum.

La voz pararayo, por otra parte, viene a designar el artificio inventado por Franklin en 174724 , tras descubrir la naturaleza eléctrica del rayo. En el DRAE-1852, la Aca-

${ }^{23}$ El concepto de fluido eléctrico fue introducido por Nollet, quien postuló la existencia de una materia eléctrica afluente y una materia eléctrica efluente para explicar los fenómenos de atracción y repulsión eléctrica. En la traducción del Ensayo (1747), esta expresión puede documentarse en diferentes ocasiones (pp. 41, 65 y 100); las expresiones corriente electrica (pp. 89, 107 y 111) y líquido electrico (pp. 64, 90 y 99) se utilizan con un sentido idéntico. Será, no obstante, la forma fluido eléctrico la habitualmente empleada en otros manuales y tratados: GIMBERNAT (1787), p. xxxii, JUGLA (1788), pp. 11 y 13. SIGAUD DE LA FOND (1792), pp. 6. 12 y 14, LiBES (1827-28), pp. 118 y 135.

L. Galvani (1791) defendió la existencia de la electricidad animal o fluido galvánico, como algo distinto del fluido eléctrico, en el transcurso de sus experimentos con las ranas. Con posterioridad, sin embargo, los estudios de Volta (1792) demostraron que no existía tal electricidad animal. Más tarde, aunque el propio Volta debía identificar dicho fluido con el eléctrico, la denominación de fluido galvánico continuaría empleándose para designar aquél. que en realidad resultaba del contacto entre dos metales (RIERA, 1989, p. 57). Tal es la situación que reflejan las definiciones ofrecidas por el DRAE, que incluirá ambos términos hasta las ediciones de 1852 (fluido galvánico) y 1869 (fluido eléctrico), los cuales no volverán ya a aparecen en sus páginas: el primero se reserva para designar el fluido surgido del frotamiento de determinados cuerpos; el segundo para el surgido del contacto entre metales. Puede verse también en el Diccionario universal de Física (1796-1802) de BRISSon (s.v. electricidad, fluido eléctrico y galvanismo).

24 El primer pararrayos se coloca en América en 1752 y en Europa en 1757 (se trata de una de las primeras contribuciones científicas del Nuevo Mundo). En España, su colocación se retrasaría hasta el 19 de septiembre de 1784, fecha de su instalación en Segovia, de manos del capitán de artillería Tomás de Morla. 
demia incluirá, bajo la misma entrada, la variante pararayos25. En cualquier caso, la incorporación de este término al léxico oficial suponía legitimar su uso frente al de guarda-rayos, anti-rayos, conductores eléctricos o barras conductoras, que podía encontrarse en otros textos ${ }^{26}$.

ParaRAYO. Máquina que se coloca sobre los edificios, que sirve para disminuir la materia eléctrica de que están cargadas las nubes (DRAE-1817)

En la definición del término ámbar, que ya se incluía en AUTORIDADES, se introduce por primera vez en esta edición la referencia a sus propiedades atractivas o eléctricas ('[...] Si se frota se hace eléctrico [...]', DRAE-1817). Otro tanto ocurre con electro, definido como sinónimo de ámbar.

Finalmente, la incorporación de una segunda acepción de electrizar, en la que se sanciona su sentido figurado -un uso que se conserva hasta nuestros días- ('met. Exaltar, avivar, inflamar el ánimo de alguno', DRAE-1817), es una prueba evidente del grado de vulgarización a que habían llegado tales términos.

En tan solo dos ediciones $\left(4^{\mathrm{a}}\right.$ y $\left.5^{\mathrm{a}}\right)$, el léxico relacionado con la electricidad se ha multiplicado por dos, pasando de las 4 acepciones de 1791 a las 10 de 1817. Ahora bien, si la incorporación de nuevas voces es por sí sola una nota destacable, no lo es menos la revisión a que se someten sus definiciones, circunstancia ya anotada en las primeras líneas del Prólogo. Así lo evidencia el hecho de que la mitad de las acepciones incluidas en 1803 experimenten algún tipo de modificación ${ }^{27}$. De ellas interesa, especialmente, la que se realiza en la explicación de la voz electricidad. Junto a la descripción de los efectos de atracción y repulsión que resultan de su acción, ya presentes en la definición de 1803, se apunta ahora la de sus efectos caloríficos y lumínicos, similares a los del rayo. Compárese aquélla con la ofrecida en 181728 :

ELECTRICIDAD. Propiedad que tienen los cuerpos en ciertos estados y circunstancias de despedir chispas azuladas á manera de rayos, de excitar fuertes conmociones, de in-

25 A partir del DRAE-1884, a cada una de las variantes corresponderá una entrada distinta. En esa edición. pararrayos (escrito con 'rr') remitirá a la voz pararrayo; a partir del DRAE-1899, la segunda remitirá a la primera.

26 En la Memoria sobre la construccion y utilidad de los para-rayos de JUGLA Y FonT pueden leerse las siguientes palabras: "Llamanse tambien estas Maquinas Guarda-rayos, Anti-rayos, Conductores eléctricos, Barras conductrices; pero mas comunmente Para-rayos" (1788, p. 4). La definición que el físico catalán ofrece de este aparato es la siguiente: "Una simple máquina compuesta de barras ó cadenas de hierro, unidas entre sí. y colocadas sobre los edificios, ó junto á ellos, que rematan por la parte superior en una barra, tambien de hierro, puntiaguda, dirigida verticalmente hácia las nubes, y por la parte inferior en otra barra ó cadena, que termina en un pozo de agua, es apta para atraer, conducir, y disipar la materia del rayo, y librar enteramente los edificios de su furor" (ibid., pp. 4-5).

27 Se trata de los términos ámbar, atractriz, electricidad, eléctrico, electrizar y rayo.

28 El término electricidad volverá a redefinirse en el DRAE- 1884. 
flamar las sustancias combustibles, y de traer y repeler los cuerpos leves que se acercan. Electricitas.

En última instancia, lo apuntado sobre estas líneas sirve para poner de manifiesto que, aunque con lentitud y no pocas dificultades, el léxico derivado del desarrollo de los conocimientos sobre la ciencia eléctrica se va abriendo paso en el diccionario académico. Otra cuestión -que no debe olvidarse- será que ese léxico, a pesar de la voluntad de la Corporación, refleje en su sanción y definición el verdadero estado y nivel de tales estudios.

Las cuatro ediciones del DRAE aparecidas en los años $1822\left(6^{\mathrm{a}}\right), 1832\left(7^{\mathrm{a}}\right), 1837$ $\left(8^{a}\right)$ y $1843\left(9^{a}\right)$ marcan un punto de retroceso respecto a la línea iniciada en 1803 , luego continuada en la edición de 1817: entre la sexta y novena impresión del diccionario académico, sólo cuatro voces (una en cada una de ellas) incrementan el caudal de los términos relacionados con el estudio de la electricidad. A pesar de las cifras, no debemos precipitarnos en nuestro juicio. El incremento de voces que se observa en las ediciones de 1803 y 1817 se debe, en gran medida, al abandono de la revisión de AUTORIDADES y a la consolidación del repertorio común. Al desplazar su interés hacia el diccionario en un solo volumen, la Academia incorpora al DRAE el material léxico que había acumulado en todas las letras desde el inicio de los trabajos de revisión. Hasta entonces, este material había visto la luz sólo parcialmente; tras las tres primeras ediciones del repertorio común, la corrección y aumento de AUTORIDADEs había alcanzado sólo la letra F.

En mi opinión, entre 1822 y 1843, la Academia no es ni más ni menos conservadora que en anteriores ediciones. Sus criterios siguen siendo los mismos, y su estandarte, el purismo y el normativismo. El rechazo sistemático a la inclusión del vocabulario científico y técnico no hace sino confirmar este parecer:

Habiéndose aumentado desmedidamente la nomenclatura de origen griego, aplicada no sólo á varias ciencias, sino á los diversos ramos que comprende cada una, acuden los curiosos al Diccionario en busca de los nombres de aquella procedencia, y no hallándolos en él, lo acusan de pobre y diminuto. La Academia se ve por tanto en la precisión de advertir, que tales nombres pertenecen menos al caudal de los idiomas vulgares, que al lenguaje técnico y peculiar de las ciencias á que se refieren. Por lo mismo no se juzga autorizada para darles lugar en su Diccionario, hasta tanto que el transcurso del tiempo los va haciendo familiares, y el uso comun los adopta y prohija $(D R A E-1837)^{29}$

29 En esta misma línea, en el Prólogo al DRAE-1843, respondiendo a aquellos que acusaban "de escasez al Diccionario académico, echando de menos en él voces que en su concepto debieran incluirse" (DRAE1832), podía leerse lo siguiente: "hay tambien una inmensa nomenclatura de las ciencias, artes y profesiones, cuyo significado deben buscar los curiosos en los vocabularios particulares de las mismas; tales voces pertenecen á todos los idiomas y á ninguno de ellos, y si hubieran de formar parte del Diccionario de la lengua comun, léjos de ser un libro manual y de moderado precio, circunstancias que constituyen su principal utilidad, seria una obra voluminosa en demasía, semienciclopédica y de difícil adquisición y manejo" (DRAE-1843). 
Volviendo sobre los nuevos términos incluidos en esas ediciones, se observa que el mayor incremento de voces se da en el campo de la 'electricidad natural': galbanismo se incorpora en el DRAE-182230; galbánico lo hace en el DRAE-1837; y centella se suma a los anteriores en el DRAE-1843. El panorama se completa con la introducción del término metaß1 en el DRAE-1832, definido como 'mineral pesado, opaco, de lustre particular, brillante aun en polvo ó arena, de color fijo, y capaz de conducir el calor y la electricidad de un cuerpo á otro'.

Las definiciones de galbánico y galbanismo, descrito como 'la propiedad de excitar movimientos espasmódicos en los nervios y músculos' -ambas con grafía 'v' a partir de 1852- se relacionan directamente con la teoría del fluido galvánico expuesta por Galvani, a la que me he referido más arriba. Precisamente, la voz galbanismo es la primera que incorpora en su explicación una marca diatécnica; se trata de la marca Med., que da cuenta de las propiedades curativas que se atribuían por entonces al fluido (en 1869 la cambiará por Fís., más adecuada).

Contra lo que pudiera pensarse, el criterio restrictivo frente a la incorporación de la terminología científica -cuya máxima expresión la constituye el Prólogo a la edición de 1843- no debía revertir necesariamente en una despreocupación por tales voces. En las diferentes ediciones, el prologuista advierte al lector de las notables mejoras que se han llevado a cabo en el interior de los artículos, "especialmente en los [...] que pertenecen á ciencias naturales, en las que los adelantamientos de estos últimos tiempos han aclarado y corregido diferentes equivocaciones que antes eran comunes" (DRAE-1817) ${ }^{32}$. La voluntad de la Academia, en este punto, es la de ofrecer definiciones exactas, esclarecedoras y actualizadas con los nuevos conocimientos científicos, huyendo al tiempo del empleo de términos facultativos; el Prólogo a la séptima edición (1832) es claro en este sentido. No se trata sólo de una declaración de intenciones; los resultados del presente estudio confirman las declaraciones de la Academia en los Prólogos a las distintas ediciones del DRAE.

30 El término se documenta con anterioridad en BRISSON (1796-1802), s.v. galvanismo, donde recibe también el nombre de influencia de Galvani y electricidad animal.

31 En la definición de metal se observa la introducción del verbo conducir con el sentido de 'transmitir el fluido eléctrico' : paradójicamente tal acepción no se incorporará en el cuerpo del diccionario hasta el DRAE1884; lo hará a través del adjetivo conductor y del sustantivo conductor eléctrico. La introducción de términos extraños al repertorio en la definición de las acepciones en él incluidas es frecuente en el caso de la nomenclatura científica y técnica.

32 No será ésta la última vez que la Academia justifique la falta de exactitud en las definiciones de las voces facultativas, amparándose en el retraso de los estudios científicos. Tal es el caso de la edición de 1832: "Las definiciones de estas en las primeras ediciones no pudieron menos de resentirse de la imperfeccion de las mismas ciencias en aquel tiempo, y después al corregirlas se convirtieron no pocas de ellas en explicaciones ó descripciones demasiado largas, porque se consideró que todavía no eran muy conocidos los objetos de que se trataba" (DRAE-1832). 


\subsection{Las ediciones de 1852 y 1869}

El repertorio de la Academia no podía permanecer ajeno a los progresos que se vivían en el terreno de los estudios científicos, y muy especialmente a sus repercusiones en el ámbito lingüístico. La firme declaración de principios con que se abre la edición de $1843\left(9^{a}\right)$, en la que la Corporación se reafirma en su criterio conservadurista, es ilustrativa de la creciente presión que el vocabulario de la ciencia y de la técnica ejercía sobre el repertorio académico. A la postre, sin embargo, el pulso que por esa fecha mantienen purismo y neologismo científico se irá decantando en favor del segundo. Las ediciones de 1852 y 1869, aunque asumirán los principios por los que se rigen las anteriores, verán notablemente incrementado el caudal de este género de voces.

La décima edición del $D R A E$, a pesar del mantenimiento del criterio conservadurista, anuncia la importante incorporación de términos procedentes "del rápido vuelo que á su sombra tutelar [la de las instituciones políticas] han tomado las artes, el comercio y la industria" (DRAE-1852). Así parece confirmarlo el incremento, con cuatro nuevas acepciones, del léxico relativo a la ciencia de la electricidad. Se trata de las siguientes palabras: galvanizar (2 acepciones), pararrayos y telégrafo eléctrico33.

Por primera vez desde la introducción de la física eléctrica en el cuerpo del repertorio, se da entrada a dos términos que resultan de su aplicación a otras disciplinas, concretamente a la telegrafía 34 y la galvanoplastia:

TELÉGRAFO ElÉctRICO. El que sirve para lo mismo35, por medio de la electricidad transmitida por alambres sostenidos á poca altura sobre el terreno, ó enterrados en este, $y$ aun sumergidos en el mar.

Galvanizar ( $2^{a}$ acepción). Emplear el galvanismo en el dorado de los metales y otras operaciones de la industria.

33 Los términos galvanizar y telégrafo eléctrico se incorporan con anterioridad en el Diccionario nacional de R. J. Domínguez (1846-47). El primero de ellos lo hará también en el Diccionario general de J. CABALLERO (1849).

34 El español Francisco Salvá I Campillo participó de manera directa en el paso de la telegrafía óptica a la telegrafía eléctrica, un proceso de perfeccionamiento progresivo y continuo que acabará con la construcción del telégrafo eléctrico de Sommerig en 1810. En este sentido, las consideraciones de Galvani sobre la electricidad animal serían aplicadas por Salvá a la telegrafía; por una vía paralela. Volta encontraba el camino hacia el descubrimiento de la pila eléctrica en 1800. Fruto del trabajo de SAlvA serían las cinco memorias que pronunciaría en el seno de la Real Academia de Ciencias Naturales y Artes de Barcelona entre 1795 y 1804 : Sobre la electricidad aplicada a la telegrafía (16-XII-1795), Disertación sobre el galvanismo (19-II-1800), Adición sobre la aplicación del galvanismo a la telegrafía (14-V-1800). Discurso sobre el galvanismo (8-VII-1801) y Memoria segunda sobre el galvanismo aplicado a la telegrafía (22-II-1804). Puede leerse un extracto-resumen de estas memorias en Agustl I Cullell (1983), pp. 66-69.

La consecuencia inmediata de los esfuerzos de SALVÁ, a los que hay que sumar el Tratado de telegrafía eléctrica de AMBROSIO GARCÉS DE MARCILLA en 1851, será la implantación de la telegrafía eléctrica en España por medio de la Real Orden del 27 de noviembre de 1852 (RIERA, 1989, pp. 59-60).

35 'para comunicar con suma brevedad noticias y órdenes por medio de signos que representan los caracteres ó letras' (DRAE-1852; s.v. telégrafo). 
Sorprendentemente, en la definición de este último término se introduce la voz galvanismo con un significado que no aparecerá hasta la siguiente edición (1869). No hay duda de que se trata de un descuido. Obsérvese la definición que ofrece el DRAE-1869, donde se sancionan ambas acepciones (la primera se corresponde exactamente con la incluida en 1852, y cambia la marca Med. con que se incorporó en 1822 por Fís., más adecuada):

Galvanismo. Fís. Propiedad de excitar, por medio de varillas de cobre y zinc, movimientos en los nervios y músculos de animales vivos ó muertos. // Electricidad desarrollada por contacto de dos metales distintos, que son regularmente el zinc y el cobre. Esta propiedad, descubierta por Galvani, dió origen á la pila de Volta y otras posteriores (DRAE-1869)

Por lo demás, la voz pararrayos y la primera acepción de galvanizar no aportan grandes novedades: la primera es, según vimos, una variante ortográfica de pararayo (incorporada en 1817); la segunda se relaciona con la aplicación del fluido galvánico, al que me he referido con anterioridad.

El cambio que parecía comenzar a gestarse en la décima edición del DRAE se hace más evidente con la aparición de la undécima en 1869. El repertorio continúa "desatendiendo el vulgar clamoreo de los que miden la riqueza de una lengua por el número de vocablos" y sigue "firme en su decisión de no sancionar más palabras nuevas que las indispensables, de recta formación, é incorporadas en el Castellano por el uso de las personas doctas" (DRAE-1869). Pero son cada vez más las palabras que reúnen tales condiciones; tanto es así que, si en la anterior impresión del repertorio académico anotaba que el léxico de la electricidad se había visto incrementado con cuatro nuevas acepciones, en esta nueva edición cabe apuntar un total de nueve incorporaciones.

El aumento más significativo en esta ocasión se produce en el ámbito de los términos relacionados con la generación (pila y par, ambos acompañados de la marca Fís. ${ }^{36}$, el almacenamiento (condensador eléctrico) ${ }^{37}$ y la conducción del fluido eléctrico

36 Ambos términos se documentan ya en LIBES [la negrita es mía]: "Esta pila se compone regularmente (fig. 151) de planchas de cobre de algunos milímetros de espesor. Encima cada una de esta planchas [...] descansa una plancha de zinc [...]. y cada par de planchas que se mira como uno de los elementos de la pila está separado por un conductor húmedo" (1827-28, p. 201). En numerosas ocasiones se habla también de pila de Volta (ibid., p. 145), pila voltaica (ibid., p. 205), pila eléctrica (ibid., p. 191) y aparato galvánico (ibid., p. 214).

El DRAE-1869 la define como 'Fís. Aparato que sirve para desenvolver la electricidad, mediante el contacto de cuerpos de distinta naturaleza; como la de Volta y otras más modernas'. Con anterioridad, se había incorporado a los repertorios de Dominguez (1846-47, s.v. Volta: pila de). CABAllero (1849, s.v. pila: pila de volta ó galvánica), CHAO (1853, s.v. pila: 'Estas pilas se llaman comunmente PILAS DE VOLTA o GALVÁNICAS') y CAMPUZANO (1869. s.v. pila: pila de Volta). En el repertorio de CHAO se incorporan además las voces pila de Bunsen, pila de cajones y pila seca de Zamboni; es éste, por otra parte, el único que incluye la voz par entre sus entradas.

37 Definido como 'Aparato para acumular electricidad' (DRAE-1869), se documenta con anterioridad en 
(aislador, marcado Fís.). A estas inclusiones se suma la incorporación de cuatro nuevas voces relacionadas con la aplicación de la electricidad a otras disciplinas, concretamente a la telegrafía (cable eléctrico y submarino) ${ }^{38}$, la electroquímica (galvanismo, y el adjetivo galvánico) ${ }^{39}$ y la galvanotecnia (galvanoplástica, marcada con Quím.) ${ }^{40}$.

Sorprende observar el distinto grado de cientificidad que presentan las definiciones incluidas en esta edición. Mientras la definición de galvanismo, que hubiera precisado ser marcada como tecnicismo, es bastante objetiva y exacta (la he reproducido con anterioridad), la de pila resulta imprecisa e incompleta (se define como aparato y no se precisa cuál es la naturaleza de los cuerpos que entran en contacto). Otra cuestión distinta es la de la pertinencia de las explicaciones que se ofrecen al final de las definiciones de galvanismo y pila, que rayan los límites del enciclopedismo. Se trata de un problema con el que tropezará frecuentemente el $D R A E$ al definir los términos técnicos.

En última instancia, la edición de 1869, que se muestra continuadora de una tendencia que se iniciaba en la anterior impresión del diccionario (1852), se caracteriza por la consolidación de la tímida, aunque creciente, apertura al léxico relacionado con la electricidad, y por extensión a la terminología científica. El DRAE se prepara para vivir, en la edición de 1884, uno de los cambios más significativos en su historia.

\subsection{La edición de 1884}

No hay duda de que la importancia que adquiere la incipiente industria eléctrica en nuestro país hacia finales del siglo XIX ${ }^{41}$ la convierte en uno de los factores que contribuyen a la eclosión del léxico relacionado con la electricidad en el DRAE a partir de su duodécima edición (1884). Pero limitar la explicación de esa inflación léxica a esta cir-

Libes (1827-28), p. 125, y en los diccionarios de Dominguez (1846-47), Caballero (1849), ChaO (1853) y CAmpuzano (1868).

38 Se incorpora con anterioridad en CHAO (1853) y CAMPUZANO (1868).

39 Ambos términos, junto a galvanizar, se documentan en LiBES (1827-28), p. 200 y en los repertorios de Domínguez (1846-47). Caballero (1849), Chao (1853) y Campuzano (1868).

40 En el DRAE-1884 se incorporará la variante galvanoplastia, también marcada Quím.; en el DRAE-1899 ambas cambiarán esta indicación por la más adecuada Fís. Precisamente esta segunda forma es la incluida con anterioridad en Dominguez (en el suplemento de la $4^{a}$ edición de 1850). Chao (1853) y Campuzano (1868).

41 La tenacidad y el empeño de unos pocos ingenieros y científicos con cierta independencia económica (Manjarres y Bofarull -director de la Escuela Industrial de Barcelona-, Paula y Rojas -director de la revista La electricidad (1883-1889)-, Dalmau y Faura, y Xifrà Masmitjana -promotores ambos de la instalación de la primera central eléctrica-) debía contribuir a la difusión en España de los nuevos conocimientos, avances y aplicaciones que la electricidad experimentaba en Europa. Al conocimiento y la difusión de las dinamos de Gramme en 1874, siguen las primeras iluminaciones con arco voltaico (1875) y la primera instalación telefónica (1877). Más tarde, la fundación de la Sociedad Española de Electricidad en 1881, que supone la consolidación de la industria eléctrica, abre un período de feroz competencia, que se manifiesta en la creación de múltiples empresas nacionales. Vid. MALuQueR (1992), pp. 121-142. 
cunstancia sería simplificar en exceso un hecho de verdadera trascendencia en la historia del repertorio académico. Existen suficientes elementos de juicio para afirmar que, respecto a la inclusión del neologismo -y por tanto del tecnicismo-, se emprende un nuevo rumbo en la empresa lexicográfica de la Corporación.

En primer lugar, no sólo el vocabulario relacionado con la ciencia de la electricidad va a experimentar un notable aumento en el conjunto del caudal léxico; también otras parcelas del ámbito científico verán notablemente incrementada su presencia en el cuerpo del repertorio. Por otra parte, las palabras del Prólogo a la edición de 1884, que se presenta como 'novedosa' desde sus primeras líneas, son suficientemente explícitas:

Otra novedad de la duodécima edición es el considerable aumento de palabras técnicas con que se ha enriquecido. Por la difusión, mayor cada día, de los conocimientos más elevados, y porque las bellas letras contemporáneas propenden á ostentar erudición científica en símiles, metáforas y todo linaje de figuras, se emplean hoy á menudo palabras técnicas en el habla común. Tal consideración, la de que en este léxico había ya términos de nomenclaturas especiales, y las reiteradas instancias de la opinión pública, lograron que la Academia resolviese aumentar con palabras de semejante índole su Diccionario; aunque sin proponerse darle carácter enciclopédico, ni acoger en él todos los tecnicismos completos de artes y ciencias (DRAE-1884).

El DRAE debía abrir sus puertas al tecnicismo como consecuencia de su cada vez más frecuente presencia en el léxico común; ahora bien, tanto o más importante que tal circunstancia, era la presión ejercida por el público en general, las empresas lexicográficas no académicas desarrolladas a partir de la mitad de siglo y la comunidad científica en particular, que precisaba nuevas formas y cauces de expresión. En última instancia, como consecuencia de este clima general, el repertorio académico, en su edición de 1884, inicia una tendencia que se alargará hasta nuestros días, dando entrada decidida en su caudal léxico a una serie de voces que circulaban desde hacía algún tiempo, no sólo en los libros científicos y técnicos, o en las obras de Domínguez, Caballero o ChaO -entre otros-42, sino también en el habla habitual y común.

42 Los repertorios no académicos aparecidos a mitad de siglo, a pesar de sus marcadas diferencias, presentan como nexo de unión característico la incorporación decidida de nuevas voces, en particular las procedentes del ámbito científico; la denuncia de la parquedad de la nomenclatura académica está presente en sus Prólogos y Advertencias al lector.

Pedro Labernia (1844) y ViCente Salva (1846) son los primeros en abrir su repertorio al tecnicismo; sus objetivos, sin embargo, no distan demasiado de los de la Academia (Salvá se presenta en el Prólogo como su adicionador). En este sentido, es preciso apuntar que el repertorio de SALVÁ cuenta con 18 acepciones relativas al estudio de la electricidad; el diccionario de LABERNIA, algo menos restrictivo, reúne un total de 25 términos, 10 de los cuales se incorporarán en posteriores ediciones al repertorio académico.

La prudente vía abierta por LABERNIA será continuada con decisión por R. J. Dominguez (1846). La publicación de su Diccionario Nacional supone el paso definitivo hacia el diccionario enciclopédico, del que serán 
Un simple recuento de las nuevas incorporaciones relativas a la ciencia de la electricidad y sus aplicaciones que se dan en la duodécima edición del DRAE (1884) permite corroborar las afirmaciones precedentes. Sólo en esta edición el corpus léxico se ve incrementado con 25 nuevas voces, es decir, casi tantas como las introducidas a lo largo de las once anteriores impresiones del repertorio académico.

El aumento más significativo es el que experimentan las voces relacionadas propiamente con el campo de la electricidad (un total de 21 términos). En este sentido, destaca la inclusión, por primera vez en el DRAE, de una serie de acepciones relacionadas con la electrometría (electrómetro, electroscopio y galvanómetro) ${ }^{43}$ y, sobre todo, la del término luz eléctrica, que se define como 'La que se obtiene por medio de la electricidad, de brillo deslumbrador, de calor muy intenso, pero que alumbra menos de lo que brilla y que llega a ofender á la vista'44. No hay duda de que la incorporación de las voces apuntadas era urgente e inaplazable.

No menos apremiante que las anteriores era la inclusión de electricidad resinosa, electricidad vítrea, electricidad positiva y electricidad negativaas, de los términos bate-

algunos de los principales ejemplos los repertorios de EduARDo ChaO (1853). José CABAllero (1849) y Ramón CAMPUZAno (1868). Tras rastrear la obra de DomínGuEz, he podido reunir hasta 116 voces relacionadas con el estudio de la electricidad. Los restantes repertorios, que siguen al primero en la mayoría de sus definiciones -incluso plagiándolo-, no se alejan demasiado de la cifra anterior: en el diccionario de CABALlero se incluyen 79 términos (76 de ellos presentes ya en DOMínGUEZ); en la obra dirigida por CHAO se da entrada a un total de 109 voces; en el repertorio de CAMPUZANO -inspirado en CHAO-, finalmente, se incorporan un total de 79 acepciones.

Las cifras ofrecidas sobre estas líneas forman parte de un trabajo que, bajo el título de "El tecnicismo en los diccionarios de mediados del siglo XIX: el léxico de la electricidad", presenté como comunicación en el xxv Simposio de la Sociedad Española de Lingüística, celebrado en la Universidad de Zaragoza en diciembre de 1995.

43 El estudio de las magnitudes eléctricas lo inaugura Ampère en 1821 con la invención del galvanómetro. Este término, junto a electrómetro (documentado en LIBES, 1827-28, p. 125) y electroscopio, se incluye con anterioridad en los diccionarios de Labernia (1844), Dominguez (1846), Caballero (1849), ChaO (1853) y CAMPUZANO (1868).

44 Este término se documenta ya en Nollet (1747), p. xlix, aunque con un sentido notablemente distinto. Nollet acude a esta expresión para describir ciertas emanaciones luminosas que resultan de la manipulación de los cuerpos eléctricos o electrizados: "De estas Experiencias, concluyò Mons. Gray, que por la comunicacion de la Electricidad se podia producir una llama actual, con explosion y ebullicion en la agua fria: y sospechò, que los relampagos, y el trueno podrian en gran parte depender de la naturaleza de este fuego, ò de esta luz electrica". La definición del DRAE-1884, en cambio, remite a la luz producida por el arco voltaico (inventado por Davy en 1816) y la lámpara de incandescencia (inventada por Edison en 1878).

45 Acuñados por Dufay en 1733, los términos electricidad vitrea y electricidad resinosa se documentan ya en Nollet: "En estas Experiencias creyò vèr Mons. du Fay dos Electricidades, una vitrea, y otra resinosa, pues el pan de oro electrizado, y repelido por el vidrio, es atraido por la materias resinosas; y el pan de oro repelido por los cuerpos resinosos, es atraido por el vidrio, y el cristàl" (1747, p. xxxiv). Cuando la doctrina de Franklin fue sustituyendo a la de Dufay y Nollet -aceptada hasta finales del siglo XVIII-. se impusieron las expresiones electricidad positiva y electricidad negativa -acuñadas por el americano en 1750-. Fue SALVÁ I CAMPILLo el primero en utilizar estos conceptos en España, en su Memoria sobre la electricidad positiva y negativa, leída en la Real Academia de Ciencias Naturales y Artes de Barcelona el 9 de enero de 1788. 
ría eléctrica46, botella de Leiden ${ }^{47}$ y electróforo ${ }^{48}$, o de las voces aislamiento, aislar, conductor y conductor eléctrico, relativas a la transmisión del fluido eléctrico, cuyos primeros estudios se sitúan alrededor de 172949. Todos estos términos, en definitiva, se incluyen por primera vez en el cuerpo del DRAE casi un siglo después -en algunos casos- de su aparición en la lengua española.

Se puede afirmar, en consecuencia, que la duodécima edición del repertorio académico supone un intento de acercar el vocabulario científico relacionado con la electricidad al nivel de los conocimientos alcanzados por esta disciplina científica. Ahora bien, esa tarea de acercamiento no se limita a la inclusión de una serie de palabras con larga andadura en la lengua española, que, por su carácter técnico, no habían tenido cabida en las páginas del $D R A E$, sino que se manifiesta también en la incorporación de un conjunto de términos verdaderamente novedosos. Tal es el caso de las voces electromotor e inducción eléctrica en el campo conceptual de la física eléctrica, pero, sobre todo, el de teléfon $0^{50}$ y sus derivados telefonía y telefónico, palabras con apenas ocho años de vida en nuestro idioma.

La actualización, en el terreno de la terminología científica, a que se somete el $D R A E$-1884 supone, por otra parte, el que numerosos términos -aunque introducidos ya en el común de la lengua- sean sentidos como tecnicismos. Esta circunstancia explica la profusión de marcas diatécnicas introducidas en esta edición; concretamente, 17 de las 25 incorporaciones presentan esta indicación: 16 de ellas lo hacen con la marca

46 Definido en el DRAE-1884 como 'Fís. Reunion de varias pilas que, comunicándose entre sí, producen grande acumulación de electricidad', se documenta con anterioridad en BRISSON (1796-1802), LIBES (182728), p. 126 -donde recibe también el nombre de batería galvánica (id., p. 202)-, DominGUEZ (1846), CABALleRo (1849), ChaO (1853) y CAMPuzano (1868).

47 'Fís. La que, llena de hojuela de cobre ú oro, sirve para recibir y acumular electricidad' (DRAE-1884, s.v. botella). Inventada en 1746, en primer lugar recibió el nombre de experimento o experiencia de Leiden (Nollet, 1747, p. 76). Ya en Gimbernat (1787), p. xxxiii, SiGAUd DE LA FOnd (1787), p. xxv y (1792), p. xi y BRISSON (1796-1802) se ofrece, además, la denominación de botella de Leyde o Leydem. Ésta será la entrada que tendrá en los diccionarios de Dominguez (1846). CHAO (1853) y CAMPUZANo (1868).

48 'Fís. Aparato que sirve para producir electricidad y se compone de un disco metálico y otro de un cuerpo mal conductor del fluido eléctrico' (DRAE-1884). Ideado por Volta en 1775, el término se documenta en GIMBERnAT (1787), p. xxxiii y SIGAUd DE LA Fond (1792), p. 290, y en los diccionarios de BRISSON (17961802). Labernia (1844). Domínguez (1846), Caballero (1849), Chao (1853) y Campuzano (1868).

49 En el ámbito de la electricidad natural, aunque no puede hablarse de incorporaciones -se trata de voces incluidas en anteriores ediciones del repertorio-, es preciso anotar la referencia a la naturaleza eléctrica en la definición de diferentes fenómenos atmosféricos (como ocurriera con rayo en el DRAE-1803, y con centella en el DRAE-1843): fuego de Santelmo, helena y relámpago.

50 'Aparato para comunicar por medio de hilos eléctricos y á larga distancia la palabra hablada y toda clase de sonidos' (DRAE-1884). El teléfono lo inventa Graham Bell en 1876, y con él nace la telefonía ('Arte de transmitir el sonido á larga distancia', DRAE-1884). La telefonía, introducida en España también por Dalmau y Xifrà, se ensaya el 26 de diciembre de 1877 en la línea Barcelona-Girona; vid. MALUQUER (1992), p. 123. 
Fís. ${ }^{51}$, una con la marca Quím. (galvanoplastia). La importancia de la presencia de estas marcas, sin embargo, no se agota con estas cifras; tanto o más significativo que lo ilustrado sobre estas líneas es el hecho de que un total de 6 voces incluidas en anteriores ediciones adquieran la marca en el DRAE-1884: atractriz, condensador eléctrico, electricidad, galvánico, galvanismo1 y galvanizar1 incorporan la indicación Fís.52.

Para terminar, apuntaré que la actualización a que se somete el DRAE-1884 se completa con una notable revisión de las definiciones incluidas en anteriores ediciones. En este sentido, las modificaciones más significativas son las de los términos electricidad, galvanismo, y telégrafo eléctrico, cuya defición reproduzco bajo estas líneas; al tiempo que presentan mayor cienticifidad, se revisten de llaneza y sencillez.

ELECTRICIDAD. Fís. Agente natural muy poderoso, que se manifiesta por atracciones y repulsiones, por chispas y penachos luminosos, por las conmociones que ocasiona en el organismo animal y por las descomposiciones químicas que produce. Se desarrolla por frotamiento, presión, calor, acción química, etc. ${ }^{53}$

Galvanismo. Fís. Electricidad que se desarrolla cuando se ponen en contacto dos cuerpos conductores.

TelÉGRAFO ElÉCTRICO. Aparato que, por medio de la electricidad, transmitida por alambres, sirve para comunicar noticias instantáneamente á larga distancia. Llámase eléctrico para diferenciarlo del óptico.

En definitiva, con la edición de 1884, el léxico de la electricidad y de sus aplicaciones, dejando atrás tímidas incursiones -especialmente importantes en las anteriores ediciones de 1852 y 1869-, se abre paso definitivamente en el cuerpo del repertorio; en su sanción y definición se observa un notable acercamiento a la realidad y actualidad científica del momento, que revierte en un significativo aumento de las marcas diatécnicas. Se ha comenzado a tender un hilo que se alargará hasta nuestros días a través de las sucesivas ediciones del DRAE.

51 Se trata de las voces electricidad resinosa, electricidad vitrea, electricidad positiva, electricidad negativa, inducción eléctrica, aislar, conductor, conductor eléctrico, polarización, electrómetro, electroscopio. galvanómetro, batería eléctrica, botella de Leiden, electróforo, electromotor.

52 Los criterios que rigen la distribución de tales indicaciones -si los hay- no se hacen explícitos en ningún momento; la labor se confía a la intuición y el buen hacer de los académicos. Sin embargo, al tiempo que se generaliza de manera importante su inclusión, comienzan a vislumbrarse las primeras incongruencias en su asignación (aislar se contempla como Fís., pero no aislamiento, que no se marca; otro tanto ocurre con inducir e inductor, etc.). Será ésta una característica que se extenderá hasta la actual edición del DRAE-1992.

53 Esta definición se conserva hasta el DRAE-1970. A partir del DRAE-1984 se incluye la siguiente, más adecuada a los conocimientos actuales sobre este agente natural: 'Fís. Agente fundamental constitutivo de la materia en forma de electrones (negativos) y protones (positivos) que normalmente se neutralizan. En el movimiento de estas partículas cargadas consiste la corriente eléctrica. // Parte de la física que estudia los fenómenos eléctricos'. 


\section{FINAL}

El seguimiento de las incorporaciones relacionadas con la electricidad en el diccionario de la Academia desde el inicio de la publicación de AuTORIDADES (1726-1739) hasta la edición del DRAE-1884, junto al examen de los prólogos a sus distintas ediciones, permite señalar la existencia de varias etapas en su dilatada historia, en relación con la introducción del vocabulario científico y técnico. Entre ellas, sin duda la más significativa es la que se inicia con la duodécima edición (1884), que marca el abandono del criterio conservadurista frente a la incorporación del tecnicismo en favor de una progresiva apertura al léxico facultativo.

Hasta llegar a ese punto de inflexión, la evolución del DRAE no es uniforme. La tres primeras ediciones en un solo tomo $(1780,1783$ y 1791) no son más que el compendio de AUTORIDADES, actualizado con las modificaciones que resultan del trabajo de revisión a que se somete la magna obra de la Academia; como aquél, lógicamente, se muestran remisas a la inclusión del léxico científico. Tampoco la consolidación del repertorio en un volumen en la edición de 1817, característica que se vislumbraba ya en el DRAE1803 , supone un cambio significativo de postura; el leve incremento que se observa en ella no es sino resultado de la generalizada actualización a que se somete la obra tras adquirir entidad propia. Se trata de una situación, en definitiva, que se mantendrá hasta la aparición de las ediciones de 1852 y 1869, donde, a pesar de la defensa de la rigidez conservadora, se abrirá paso un considerable número de voces procedentes del ámbito científico, que singularizan, al tiempo que anticipan, el definitivo tránsito hacia la inflación léxica en la duodécima edición del $D R A E$ (1884). A partir de este momento, la inclusión de la terminología científica en sus páginas será una nota común en las sucesivas ediciones del repertorio académico aparecidas hasta hoy.

En última instancia, con los resultados de la investigación presentada en estas páginas, que podría hacerse extensiva a otras parcelas del léxico corporativo, se pretende abundar y avanzar en el desarrollo de los estudios sobre lexicología histórica, que han de resultar útiles y aplicables a la confección de un diccionario histórico, una tarea hoy inacabada y, sin embargo, reclamada insistentemente por los estudiosos de la ciencia lexicográfica.

\section{Bibliografía}

Abellán, José Luis (1993): Historia crítica del pensamiento español. Del Barroco a la llustración IIII (siglos XVII y XVIII), Madrid, Círculo de Lectores.

Agusti I Cullell. JAume (1983): Ciència i tècnica a Catalunya en el segle XVIII. La introducció de la màquina de vapor. Barcelona, Institut d’Estudis Catalans. 
Alvar Ezquerra, Manuel (1983): “Los prólogos del Diccionario académico: nomenclatura específica y microestructura", Revista de Filología Española, 63, pp. 205-222.

Alvar Ezquerra, Manuel (1985): "El Diccionario de la Academia a través de sus prólogos", Philologica Hispaniensia in honorem Manuel Alvar, vol. II, Madrid, Gredos, pp. 33-44.

Alvar Ezquerra, Manuel (1992): "Tradición en los diccionarios del español", Revista Española de Lingüistica, 22, pp. 1-23.

Alvar EzQUeRRA, Manuel (1993): Lexicografía descriptiva, Barcelona, Vox-Biblograf.

Anglada, Emilia y Maria Bargalló (1992): "Principios de lexicografía moderna en diccionarios del siglo XIX", Il Congreso Internacional de Historia de la Lengua Española, Madrid, Pabellón de España, pp. 955-962.

AUTORIDADES-1726: REAL ACADEMIA ESPAÑOLA (1726-1739): Diccionario de la lengua castellana, Madrid, Francisco del Hierro (ed. facsímil, Madrid, Gredos, 1984).

AUTORIDADES-1770: REAL ACADEMIA ESPAÑOLA (1770): Diccionario de la lengua castellana, Madrid. J. Ibarra (A-B).

BRISSON, MATHURIN JACQUeS (1796-1802): Diccionario universal de fisica (trad. por C. C. y F. X. C.), 9 vols., Madrid, Benito Cano.

CABAlleRo, José (1849): Diccionario general de la lengua castellana, Madrid, Vda. de D. R. J. Domínguez, $2^{\mathrm{a}}$ ed.

Campuzano, Ramón (1868): Novísimo diccionario de la lengua castellana, Madrid, Campuzano Hnos.

CANBY, EDWARD (1965): Historia de la electricidad, Madrid, Continente.

Carrete Parrondo, Juan (1983): Difusión de las ciencias en la España ilustrada, Madrid, CSIC.

Chao, Eduardo (1853): Diccionario enciclopédico de la lengua española, Madrid. Gaspar y Roig. $1860,2^{\mathrm{a}} \mathrm{ed}$.

Corominas, Joan y José Antonio Pascual (1980): Diccionario crítico etimológico castellano e hispánico, Madrid, Gredos, 1991, $3^{\mathrm{a}}$ reimp.

DevauX, PierRe (1949): Historia de la electricidad (vers. española de Zoé Ramírez), Barcelona, Salvat.

DomínGuez, Ramón Joaquín (1846): Diccionario nacional o gran diccionario clásico de la lengua española, Madrid, Imprenta de Mellado, 1850, $4^{\mathrm{a}} \mathrm{ed}$.

DRAE-1780: REAL ACADEMIA ESPAÑola (1780): Diccionario de la lengua castellana, Madrid, J. Ibarra (ed. facs. en Madrid, Espasa-Calpe, 1991).

DRAE-1783: REAL ACADEMIA ESPAÑola (1783): Diccionario de la lengua castellana, Madrid, J. Ibarra, $2^{\mathrm{a}}$ ed.

DRAE-1791: Real ACAdemia Española (1791): Diccionario de la lengua castellana, Madrid, V. de J. Ibarra, $3^{\mathrm{a} e d .}$

DRAE-1803: ReAl ACAdemia Española (1803): Diccionario de la lengua castellana, Madrid, V. de J. Ibarra, $4^{\mathrm{a}}$ ed.

DRAE-1817: Real ACADEMIA Española (1817): Diccionario de la lengua castellana, Madrid, Imprenta Real, $5^{\mathrm{a}}$ ed.

DRAE-1822: ACADEMIA ESPAÑOLA (1822): Diccionario de la lengua castellana, Madrid, Imprenta Real, $6^{\mathrm{a}}$ ed.

DRAE-1832: ACADEMIA Española (1832): Diccionario de la lengua castellana, Madrid, Imprenta Real, $7^{\mathrm{a}}$ ed.

DRAE-1837: ACADEMIA ESPAÑola (1837): Diccionario de la lengua castellana, Madrid, Imprenta Nacional, $8^{\mathrm{a}}$ ed.

DRAE-1843: ACAdemia Española (1843): Diccionario de la lengua castellana, Madrid, F. Ma Fernández, $9^{\mathrm{a}}$ ed. 
DRAE-1852: ACADEMIA ESPAÑola (1852): Diccionario de la lengua castellana, Madrid, Imprenta Nacional, $10^{\mathrm{a}}$ ed.

DRAE-1869: ACADEMIA ESPAÑola (1869): Diccionario de la lengua castellana, Madrid, M. Rivadeneyra, $11^{\mathrm{a}}$ ed.

DRAE-1884: ReAl AcAdemia Española (1884): Diccionario de la lengua castellana, Madrid, Hernando y $\mathrm{Cia}, 12^{\mathrm{a}}$ ed.

DRAE-1899: Real ACAdemia Española (1899): Diccionario de la lengua castellana, Madrid, Hernando y $\mathrm{Cia}, 13^{\mathrm{a}} \mathrm{ed}$.

DRAE-1984: ReAl ACADEMIA ESPAÑola (1984): Diccionario de la lengua española, Madrid, EspasaCalpe, $20^{\mathrm{a}}$ ed.

DRAE-1992: ReAl ACADEMIA Española (1992): Diccionario de la lengua española, Madrid, EspasaCalpe, $21^{\text {a }}$ ed.

Fries, DaGmar (1989): La Real Academia Española ante el uso de la lengua (1713-1973), Madrid, S.G.E.L.

GaRRIGA, Cecilio (1995): “Apuntes sobre la incorporación del léxico de la química al español: la influencia de Lavoisier", 1648-1815: L'Universalité» du Français et sa présence dans la Péninsule lbérique, en prensa.

GarRIGA, CeCILIO (1996): "Notas al léxico económico del siglo XVIII", Actas del III Congreso Internacional de Historia de la Lengua Española, Madrid, Arco-Libros, pp. 1279-1288.

Gilı Gaya, Samuel (1963): La lexicografia académica del siglo XVIII, Oviedo, Universidad de Oviedo.

Gimbernat, Carlos (1787): Exercicio publico de fisica experimental, Madrid, Alfonso López.

GutiérRez RodiLla, BERTHA M. (1993): "Los términos relacionados con la medicina en el Diccionario de Autoridades", Boletín de la Real Academia Española. 73, pp. 463-512.

GUTIÉRREZ RodiLLA, BERTHA M. (1996): "El léxico de la medicina en el diccionario de Esteban de Terreros y Pando". Actas del III Congreso Internacional de Historia de la Lengua Española. Madrid, Arco-Libros, pp. 1327-1342.

JUGlA y Font, ANTONI (1788): Memoria sobre la construccion y utilidad de los Para-Rayos, leída a la Real Academia de Ciencias Naturales y Artes de Barcelona en las Juntas Literarias de 10 de enero y 14 de marzo de 1787, Barcelona, Suriá y Burgada.

LABERNIA, PEDRO (1844): Diccionario de la lengua castellana con las correspondencias catalana y latina, Barcelona, Imprenta de D. J. M. de Grau.

Lázaro Carreter. Fernando (1973): Crónica del Diccionario de Autoridades (1713-1740). Madrid, Real Academia Española.

LÁzaro CaRreter, Fernando (1985): “Neologismo y purismo", Las ideas lingüísticas en España durante el siglo XVIII, Barcelona, Crítica, pp. 245-282.

LIBES, ANTOINE (1827-28): Tratado de física completo y elemental (trad. P. Vieta), 3 vols., Barcelona, Vda. e hijos de Brusi.

López Piñero, José MARÍA (1969): La introducción de la ciencia moderna en España, Barcelona. Ariel.

López PIÑERo, José María (1979): Ciencia y técnica en la sociedad española de los siglos XVI y XVII, Barcelona, Labor.

MALUQUER DE MOTES, JORDI (1992): "Los pioneros de la segunda revolución industrial en España: la Sociedad Española de Electricidad (1881-1894)", Revista de Historia Industrial, 2, pp. 121-141.

MaRTínez BaRRIOS, Luis (1994): Historia de las máquinas eléctricas, Barcelona, U.P. C.

MORENO, JOSÉ ANTONIO (1995): "Jean-Antoine Nollet y la difusión del estudio de la electricidad: un nuevo léxico para una nueva ciencia”, 1648-1815: L' «Universalité» du Français et sa présence dans la Péninsule lbérique, en prensa. 
Navarro y Abel de Veas, Benito (1752): Physica Electrica, ó Compendio, en que se explican los maravillosos phenómenos de la virtud eléctrica, Madrid, Bardón.

Nollet, Jean-Antoine (1747): Ensayo sobre la electricidad de los cuerpos (trad. de J. Vázquez y Morales), Madrid, Imprenta del Mercurio.

Nollet, JeAn-Antolne (1757): Lecciones de física experimental (trad. de J. Zacagnini), Madrid, Ibarra.

Pascual, José Antonio y Juan GutiérRez Cuadrado (1992): "Prólogo a propósito de las actas del Congreso Literario Hispano-Americano de 1892". Congreso Literario Hispano-Americano (1892), Madrid, Instituto Cervantes - Pabellón de España - Biblioteca Nacional, pp. ix-xxxi.

Planell Riera, Francesc (1950): Etapas memorables en la historia de la ciencia de la electricidad, Barcelona, Escuela de Peritos Industriales.

Rieger, Christian (1763): Observaciones Physicas sobre la Fuerza Eléctrica (trad. de M. de Benavente), Madrid, J. Ibarra.

Riera I TuÉbols, Santiago (1983): Síntesi d'història de la ciència catalana, Barcelona, La Magrana.

Riera I Tuébols, SANTiago (1989): Ciència i tècnica a la Il.lustració: Francesc Salvá i Campillo, Barcelona, La Magrana.

Rodríguez, Francisco (1996): "El léxico de los "caminos de hierro" en español", Actas del III Congreso Internacional de Historia de la Lengua Española. Madrid. Arco-Libros, pp. 15111519.

Rosmorduc, Jan (1994): Una història de la física, Barcelona, Publicacions de l’Abadia de Montserrat.

SAlvá, Vicente (1846): Nuevo diccionario de la lengua castellana, Madrid, Imprenta de H. Fournier, $1857,5^{\mathrm{a}}$ ed.

SAN VICENTE, FÉlix (1996): “Lexicografía y catalogación de nuevos saberes en España durante el siglo XVIII”, en J. Álvarez Barrientos y J. Checa Beltrán, coords., El siglo que llaman ilustrado. Homenaje a Francisco Aguilar Piñal, Madrid, CSIC, pp. 781-794.

Seco, Manuel (1987): Estudios de lexicografía española, Madrid, Paraninfo.

Seco. Manuel (1991): "Introducción". Real Academia Española (1780): Diccionario de la lengua castellana (ed. facsímil), Madrid, Espasa-Calpe, pp. III-XII.

SigAUd DE LA Fond, JoSEPH-Aignan (1787): Elementos de física teórica y experimental (trad. de T. Lope), 7 vols., Madrid, Imprenta Real.

SigAUd DE LA Fond, JOSEPH-AIGNAN (1792): Resumen histórico y experimental de los fenómenos eléctricos, desde el origen de este descubrimiento hasta el día (trad. de T. Lope), Madrid. Imprenta Real.

Still. Alfred (1947): El alma del ámbar (historia de la electricidad), Buenos Aires, Sudamericana.

TERREROS y PANDO, ESTEBAN DE (1786-1793): Diccionario castellano con las voces de ciencias y artes, ed. facsímil y presentación de Manuel Alvar Ezquerra, Madrid, Arco Libros, 1987.

Vernet, Juan (1975): Historia de la ciencia española, Madrid, Instituto de España. 